\title{
Corrupción como problema de acción colectiva: Hacia un enfoque más ajustado para pensar la reforma institucional en América Latina $\left(^{*}\right)$
}

\section{Corruption as a collective action problem: Towards a more adjusted approach to thinking about institutional reform in Latin America}

\section{Andy Philipps Zeballos (**) \\ Proética-Capítulo peruano de Transparencia Internacional \\ ORCID: 0000-0002-6746-7268}

Fecha de recepción: 24 de agosto

Fecha de aceptación: 13 de noviembre

ISSN en línea: $2415-2498$

Philipps Zeballos, A. (2018) «Corrupción como problema de acción colectiva: Hacia un enfoque más ajustado para pensar la reforma institucional en América Latina». Politai: Revista de Ciencia Política, Año 9, segundo semestre, № 17, pp. 176- 211

DOI: https://doi.org/10.18800/politai.201802.006

${ }^{*}$ ) El presente artículo recoge parte de la investigación realizada para «La corrupción como problema de acción colectiva: la confianza, las instituciones y la República de Corea como estudio de caso», tesis para optar el grado de Magíster en Corrupción y Estado de Derecho en la Universidad de Salamanca.

$\left.{ }^{* *}\right)$ Politólogo por la Universidad Complutense de Madrid y la Universidad de Essex, Magíster en Corrupción y Estado de Derecho por la Universidad de Salamanca. Editor de Política en United Explanations. Realiza consultorías a instituciones del ámbito público y privado. andyphize@live.com 


\title{
Sumilla
}

Entendemos, como Kafka al referirse a la situación de la burocracia de principios de siglo XX en Europa en 'El proceso', que una de las raíces de la corrupción es la falta de sentido de conjunto. En el presente artículo proponemos superar el enfoque de rational choice para combinarlo con uno que piense la corrupción como problema de acción colectiva. Para ello, reflexionamos sobre las siguientes cuestiones clave para comprender este enfoque: a) qué es un problema de acción colectiva, de lo que se desprende que altos niveles de confianza se asocian de manera significativa con bajos niveles de corrupción, b) cuándo podemos hablar de sociedades donde la corrupción es más la norma que la excepción, de lo que se deduce que la confianza está en juego, sobre todo, en las instituciones cotidianas, y c) en qué grado el entorno determina el comportamiento humano de acuerdo a la psicología social. Así, este nuevo paradigma ubica a las instituciones cotidianas de la administración pública en el centro de las políticas anticorrupción y nos da pistas sobre qué características de las mismas importan sobremanera para conseguir más confianza, mayor cooperación y, finalmente, menos corrupción en un Estado.

Palabras clave: enfoque anticorrupción, agente-principal, acción colectiva, reforma, confianza, instituciones cotidianas, América Latina.

\begin{abstract}
:
We understand, as Kafka does in The Trial, that one of the roots of corruption is the lack of a sense of community. In this article, we propose to overcome the rational choice approach by combining it with another one that helps understand corruption as collective action. In order to understand this approach, we reflect on the following questions: a) What is a collective action problem? b) When can we talk about societies where corruption is more the norm than an exception? and c) In which degree does the environment determine human behavior according to social psychology? Thus, this new paradigm addresses institutions of public administration in the middle of anti-corruption policies and provides us of with clues about what characteristics are key to increase confidence, promote cooperation and, finally, decrease corruption in a state.
\end{abstract}

Keywords: anti-corruption approach, main agent, collective action, reform, confidence, institution, Latin America.

\section{Introducción}


Teniendo en cuenta la falta de sentido del conjunto, ¿cómo evitar la peor de las corrupciones entre los funcionarios?

Franz Kafka, El proceso

Como es sabido, la corrupción, incluso en su definición más restrictiva relacionada con soborno y cohecho, es un fenómeno que se produce en todo el mundo, desde pequeñas asociaciones de empresarios hasta grandes organizaciones intergubernamentales y desde ámbitos aparentemente tan dispares como la financiación de partidos hasta la gestión de eventos deportivos. La corrupción traspasa los límites del Estado o las instituciones gubernamentales y puede encontrarse en sectores tan clave y generalmente no relacionados con ella como la extracción de fondos destinados a subvencionar la educación (Transparencia Internacional, 2013) o la gestión de la purificación del agua potable (Transparencia Internacional, 2010), pasando por la tan necesitada -y actualmente escasaayuda al desarrollo o cooperación internacional (Transparencia Internacional, 2014). Sus consecuencias pueden llegar a ser nefastas para el desarrollo económico y social de cualquier Estado. En lugar de «engrasar el sistema», contribuye a perpetuar políticas públicas cortoplacistas y de mediano alcance, así como a sustentar las desigualdades socioeconómicas y la deslegitimación del propio régimen ${ }^{1}$ por parte de la ciudadanía. Es más, algunos autores afirman que la corrupción en algunos Estados del Medio Oriente estaría provocando la expansión del terrorismo internacional (Chayes, 2015, p.7).

A pesar de que la corrupción se encuentra en diversos sectores de la sociedad, la que más parece haber contribuido a esta suerte de «enmienda a la totalidad»-que muchos ciudadanos realizan sobre la democracia- es la corrupción en el gobierno (presidente, parlamentarios, altos órganos de justicia, entre otros). Esto ha conducido, como señalan Dahlström et al., a que la literatura sobre la corrupción se haya centrado en la corrupción política o «gran corrupción» (2009: 3), en desmedro de las posibilidades que se pueden abrir a través de las reformas en otro tipo de instituciones o sectores de la sociedad.

\footnotetext{
${ }^{1}$ Robert Dahl distingue sistema político de régimen político. El primero se relaciona con la estructura de organización formal de un Estado y el segundo, con la forma en la que se rigen las relaciones entre los distintos actores políticos.
} 
Por otro lado, aunque pueda resultar evidente que las instituciones gubernamentales necesiten reformas anticorrupción, lo que no parece tan claro es por qué éste tipo de instituciones las requieren por encima de otras, ni tampoco por qué debemos centrarnos en los cargos políticos (electos y teóricamente temporales) y no en otras instancias de la administración pública, la sociedad civil, la influencia de las organizaciones internacionales (OIG en adelante) o el sector privado. En este sentido, cabe cuestionarse a qué tipo de enfoque o a qué premisas e intereses responden las reformas centradas en la transparencia y en las sanciones más duras a la «corrupción política», y si han producido resultados positivos.

En el presente artículo analizaremos brevemente el efecto de los enfoques «culturalista» ${ }^{2} \mathrm{y}$ de agente-principal, ambos especialmente presentes en América Latina mediante algunas de las reformas anticorrupción que han propuesto y que, en algunos casos, han contribuido a la construcción de un discurso hegemónico sobre la corrupción, a veces pesimista y engañoso (Orlando, 2004; Gil Villa, 2013). De este modo, justificaremos por qué es necesaria una revisión de enfoque desde el punto de vista teóricometodológico, especialmente en aquellos contextos donde la corrupción es más la regla que excepción.

Cabe recordar que los enfoques relacionados con la corrupción han pretendido hallar las causas de esta para formular determinadas políticas públicas y reformas que la reduzcan. Así, aunque observar la corrupción como problema de acción colectiva presenta dificultades a la hora de plantear políticas públicas (PP en adelante) anticorrupción (AC en adelante) (Mungiu-Pippidi, 2013, p.108), aporta nuevos elementos al debate en torno a por qué se genera y cómo se la puede combatir desde las instituciones. El primero de esos aportes es hacer notar a algunos órganos de poder (Estados, OIG, ONG, etc.) que determinadas sociedades se encuentran en una especie de trampa (Rothstein, 2005), dilema social (Ostrom, 1998) o círculo vicioso (Jiménez, 2014) (Ver gráfico 1) del cual no se podrá salir si desde las reformas AC se continúa observando el problema como cultural, individual/racional o monocausal. Una vez

\footnotetext{
${ }^{2}$ Este término ya es utilizado por Jiménez en «La trampa política: la corrupción como problema de acción colectiva» (2014).
} 
revisados estos dos enfoques $\mathrm{AC}$, se presentará y reflexionará sobre las implicancias del enfoque que toma la corrupción como problema de acción colectiva.

\section{El enfoque culturalista}

En uno de sus textos menos conocidos, Modernización y Corrupción (1968), Samuel P. Huntington relaciona directamente altos niveles de corrupción con falta de modernización política estableciendo que «Las diferencias entre los niveles de corrupción entre las sociedades "modernas" y "desarrolladas" del "mundo Atlántico" respecto a Latinoamérica, África y Asia, reflejan en gran medida las diferencias de la modernización y desarrollo político» (Huntington, 1968 p.253). Además, asocia la falta de reformas del Estado en el sentido de promover los principios de honestidad, probidad, universalismo y mérito con el problema de la corrupción señalando la cultura como uno de los principales obstáculos para llevar a cabo estas reformas porque «Si la cultura de la sociedad no distingue entre el rol del rey como una persona privada y su rol como Rey, es imposible acusar al rey de corrupción cuando toma dinero público (...) entonces sólo cuando tal distinción es clara, es posible comenzar a definir algunos comportamientos como corruptos» (Huntington, 1968, p.254). Este razonamiento finalmente conduce a Huntington a decir, en una suerte de predicción culturalista, que los países «mulatos» de América Latina (Panamá, Cuba, Venezuela, Brasil, República Dominicana y Haití) tendrán más altos niveles de corrupción ya que parece haber mayor desigualdad y mucha menor rigidez en la estructura social que en los países «indios» (México, Ecuador, Guatemala, Perú y Bolivia) o países «mestizos» (Chile, Colombia, El Salvador, Honduras, Nicaragua, Paraguay) (Huntington, 1968, p.258). En resumen, su propuesta de modernización del Estado tendría como objetivo principal contrarrestar la cultura de algunas sociedades que mantendrían «normas tradicionales» e impedirían alcanzar los principios deseables bajo los cuales las instituciones funcionan.

Uno de los primeros y más influyentes autores que introducen los factores culturales en la academia es Max Weber mediante La Ética Protestante y el Espiritu Capitalista (1905). El autor pretendía explicar las diferencias 
entre el desarrollo industrial de los países protestantes y el resto del mundo. Así, Huntington no es el único que utiliza un enfoque culturalista para estudiar la corrupción, aunque sí es uno de los primeros autores que plantean reformas del sistema político y económico con el fin de cambiar o debilitar las instituciones tradicionales/culturales en cuanto a la interacción con el Estado. De la misma forma, Inglehart (1990) encontró que el 75\% de la variación en el índice de la percepción de la corrupción se explicaba por factores culturales. Al igual que el autor anterior, aseguró que la convivencia de «valores tradicionales» con iniciativas para la modernización del Estado sería un detonante de actos de corrupción.

Los estudios sobre la corrupción desde una óptica culturalista parecen sugerir que, para que la relación de los ciudadanos con los recursos públicos cambie, las preferencias y creencias/ideas de la sociedad deben cambiar primero. Esto deja a las culturas anglosajonas y a la religión protestante como paradigmas de desarrollo económico y probidad, y obvia otras variables. Más adelante se entendió que, aunque la cultura influye en las preferencias, ideas y pautas de comportamiento de los individuos, no es determinante ni suficientemente explicativa. Así, por ejemplo, aunque La Porta et al. mostraron en 1997 que el catolicismo y el islam tenían un efecto positivo en la corrupción debido a su composición jerárquica, años más tarde y con una muestra más grande, la asociación encontrada anteriormente fue catalogada de débil por los mismos autores (La Porta et al., 1999) y por Shadabi (2013). Esta última llegó a dos conclusiones: a) que es el número de religiones, antes que el tipo de religión, lo que se asocia con altos niveles de corrupción (IPC de TI) ya que la religión en general funciona como una barrera interna para evitar «malas acciones/pecados» y b) que la corrupción y su control no son el resultado de ninguna religión en sí misma, ya que son las instituciones y el gobierno quienes imponen mayoritariamente las normas dentro de su jurisdicción y competencias. En todo caso, el factor religioso tiende a perder peso en favor del Estado y los medios de comunicación, ya que son estos los actuales creadores de normas sociales tanto formales como informales (Shadabi, 2013).

En esta línea, también se pueden encontrar trabajos que hablan de «cultura la corrupción»(Smith, 2007; Gil Villa, 2008) para referirse a ciertos escenarios donde la corrupción ha sido banalizada o asumida como normal 
por la mayoría de los integrantes de una sociedad. En estos lugares, la corrupción, aunque criticada, es aceptada como sustitución de los medios formales para establecer intercambios no solo entre público-privado, sino entre privado-privado (por ejemplo, en la firma de un contrato de venta de bienes raíces). En este sentido, Smith señala sobre sus más de 20 años de experiencia en Nigeria que la corrupción está en todas partes y que la vasta mayoría de nigerianos ha interactuado con ella a tal punto que esta es conocida como «the Nigerian factor» (Smith, 2007, p.86). En la misma línea, Gil Villa dice sobre México que «la corrupción ha alcanzado un tratamiento popular en clave de humor como si fuera una operación de inversión conceptual, dando la vuelta a la versión oficial y extrayendo lo positivo de lo negativo» (2008, p.271), como puede ilustrarse en el siguiente chiste:

¿Sabe usted por qué los mexicanos no somos campeones en corrupción, sino subcampeones? Porque nos han pagado para ocupar el segundo puesto (Gil Villa, 2008, p.270).

Parafraseando a Gil Villa podríamos decir que, más que la cultura de la corrupción o una cultura corrupta, esta forma de corrupción (buropolítica) que forma parte del día a día de los individuos de determinada sociedad está modificando la cultura en sí misma. Esto condujo (y conduce) a algunos académicos a entender que se debía cambiar la sociedad para cambiar las instituciones. Este discurso caló en parte de la academia, pero especialmente en el imaginario colectivo popular (Gil Villa, 2008). Por lo tanto, cambiar el discurso que se ha promovido desde estos sectores es tan importante en las sociedades poscoloniales como cambiar el enfoque a fin de revertir lo que Gil Villa ha denominado «el mensaje pesimista de los discursos sobre la corrupción» (Gil Villa, 2010).

¿En qué se traduce esto en términos prácticos? Rothstein señala que todos queremos hacer «lo correcto»-funcionarios especialmente ${ }^{3}$ - (abstenerse

\footnotetext{
${ }^{3}$ Decimos funcionarios especialmente ya que éstos estarán constreñidos de manera formal por normas y leyes, que les hacen regirse por unos determinados principios relacionados con la legalidad a priori, y, hasta cierto punto, de manera informal, por la sociedad al otorgarles ciertos valores relacionados con la ética, entre
} 
de ser oportunistas y avariciosos) pero no queremos «ser los únicos» (2000, p.9). Si los individuos tienen la noción de que «los otros» tienen una cierta tendencia a cumplir la ley, probablemente ellos también lo harán. ¿Y de dónde vendrá la información de que «los otros» cooperarán? Sobre todo, de la micro-interacción social (Ostrom, 1998) (repetición y conocimiento de los participantes), de los discursos de los expertos (Gil Villa, 2013), de la memoria colectiva (Rothstein, 2000) y de los medios de comunicación.

El enfoque culturalista puede ilustrar buena parte de las consecuencias de la corrupción generalizada en la cultura pero no al revés, ya que se entiende que ninguna cultura es más corruptible que otra si cuenta con los medios de control AC necesarios.

Con el tiempo, se pensó que los modelos de control de la corrupción de algunas empresas en los Estados Unidos podrían ser válidos para la administración pública. Este modelo fue llamado la teoría del agenteprincipal (a-p en adelante).

\section{El Enfoque agente-principal o racionalista}

El enfoque agente-principal nace de la teoría empresarial a principios de los ochentas acerca de los problemas que los accionistas (el principal) pueden tener a la hora de ejercer control sobre los directivos profesionales (el agente) (Lozano et al., 2003, p.226), ámbito en el cual han conseguido resultados positivos en términos de mayor control y transparencia (Lozano et al., 2003, p.240) y que es todavía utilizado para articular códigos de buena conducta y medidas internas en el sector privado (Lozano et al., 2003, p.230).

Esta perspectiva se fundamenta básicamente en dos ideas: a) la presunción de que el agente y el principal tendrán normalmente intereses diversos y b) que el agente tendrá casi siempre más información que el principal, lo cual conducirá a una mayor discrecionalidad por parte de aquel que buscará satisfacer sus intereses a costa de los de este.

otros. 
El funcionario o empleado público (agente) podrá abusar de su posición y discrecionalidad para reducir la calidad de los servicios, dañar el erario público y asegurarse una comisión o renta, ya que la ciudadanía y los representados son incapaces, aunque así lo quieran, de monitorear con efectividad o establecer una rendición de cuentas (Rose-Ackerman, 1978; Klitgaard, 1988; Bardhan, 1997). En otras palabras, el agente es tomado como un individuo que realiza constantes cálculos de modo que sus acciones u omisiones le reporten el mayor beneficio posible. Asimismo, la mayor información del agente hace imposible el monitoreo por parte del principal. Esta lógica, que se basa en el utilitarismo clásico, se renovó posteriormente con el aporte de la teoría liberal y tras una serie de variantes fue llamada rational choice. Una de esas variantes es situar al individuo en un libre mercado permanente, en el cual cada vez que hace una elección (que, a su vez, implica infinitas no-elecciones) es consciente de ella, porque la hace en búsqueda de su bienestar o felicidad personal y con un alto grado de información sobre aquello que está eligiendo -y lo que no- ya que ¿quién mejor que uno mismo para saber qué es lo mejor para uno o qué le hará más feliz?

El combate contra la corrupción, enfocado como un problema de a-p, tomará así al individuo como un ser racional cuyo involucramiento en un acto de corrupción será fruto de la elección racional, es decir, un cálculo entre la probabilidad de tener éxito (el beneficio en forma de reputación o dinero) y la de ser sancionado (el monto de la multa más el daño a su imagen) por el delito (Rose-Ackerman, 1978; Klitgaard, 1988; Shleifer y Vishny, 1993; Rodríguez, 2004).

Así, el modelo a-p, a diferencia del enfoque culturalista, vuelve el foco de atención al individuo, especialmente hacia el agente, al asumirlo como ser racional y potencialmente «corrompible», por lo que será necesario controlarlo (monitoreo a través de la transparencia, gobierno abierto, etc.). En el caso de que, aun así, se involucre en un acto corrupto, será preciso sancionarlo (incrementando la probabilidad de sanción a través de nuevos tipos penales, mecanismos de investigación, etc.). Se asume, además, que el principal (la ciudadanía o el representado) va a ejercer esta función. La sanción no sólo funciona como castigo, claro está, sino como elemento disuasorio a imponer por la justicia luego de que el corrupto sea denunciado por el principal. Esta es una lógica aparentemente sencilla y 
efectiva que han guiado gran parte de las recomendaciones e iniciativas anticorrupción de alguno de los más influyentes organismos intergubernamentales, así como de algunas ONG durante el último cuarto de siglo hasta nuestros días.

\section{El fracaso de las reformas generadas a partir del enfoque agente- principal}

En los últimos años, tras una época de intentos de reformas y políticas AC, se puede decir que entre buena parte de economistas y politólogos entendidos en la materia flota una idea: las reformas anticorrupción han fallado. De hecho, en países con altos niveles de corrupción como los de América Latina, el problema podría haber empeorado (Johnston, 2005; Mungiu-Pippidi 2006; Lawson, 2009; Persson/Rothstein/Teorell 2012; Jiménez 2014; Marquette y Peiffer, 2015).

Estas políticas se han aplicado en múltiples Estados miembros de la comunidad internacional, especialmente en la década de los noventas. Sin embargo, se puede destacar el caso latinoamericano como paradigmático en el sentido de que es una región que ha firmado y ratificado una gran mayoría de convenciones internacionales sin conseguir mayores avances en el IPC de TI ni en el índice de control efectivo de la corrupción (CC en adelante) del Banco Mundial ${ }^{4}$ (BM en adelante). Para empezar, en 1997 se creó la Oficina sobre Drogas y Crimen de las Naciones Unidas (UNODC) siendo la corrupción ${ }^{5}$ uno de los principales temas a tratar. De esta manera, en el año 2003, la UNODC impulsó la Convención de las Naciones Unidas Anticorrupción 2003 (UNCAC), la cual promueve la cooperación jurídica internacional (pp. 31-43), el reconocimiento y unificación de tipos penales (pp.18-30) y técnicas de investigación (pp. 51-54), así como la transparencia (pp. 9-11) y la participación ciudadana en los asuntos públicos y privados (pp.15-16), entre otros. La UNCAC es probablemente uno de los mayores esfuerzos en términos de cooperación internacional, especialmente desde la perspectiva jurídica, y es amplia, en el sentido que

\footnotetext{
${ }^{4}$ Disponible en: http://info.worldbank.org/governance/wgi/index.aspx\#reports

${ }^{5} \mathrm{La}$ corrupción es definida por la UNODC como «un problema social político y económico complejo (...) que socava la democracia, ralentiza el desarrollo económico y contribuye a la inestabilidad gubernamental».Fuente: Página web de UNODC. http://www.unodc.org/unodc/corruption/
} 
se confronta con múltiples manifestaciones de la corrupción en el mundo. La UNCAC apela a las leyes, a los gobiernos y a la sociedad civil para hacer cumplir con el Estado de Derecho, robusteciéndolo y armonizando los unos a los otros. De hecho, tras 10 años de aprobarse, 140 Estados han firmado el Convenio, lo cual ha ayudado a generar nuevas leyes o completar leyes anteriores que intentan luchar contra la corrupción.

Colombia es uno de esos Estados que ha seguido las recomendaciones desde 2003; no obstante, en su Estatuto Anticorrupción (2011) reconoce que, pese a haber ratificado tratados y convenios internacionales en virtud de los cuales ha expedido leyes y decretos para perseguir los actos de corrupción y a sus actores, no ha conseguido grandes avances ${ }^{6}$ en la lucha contra este fenómeno (2011, p.7). Entre las leyes y decretos a los que se refiere, se encuentran aquellos que han llevado a la creación de contralorías, veedurías ciudadanas y procuradurías tanto a nivel nacional como regional; se ha reforzado también al Defensor del Pueblo; se ha creado un Programa Presidencial de Modernización, Eficiencia, Transparencia y Lucha contra la Corrupción, un Consejo Presidencial para el Buen Gobierno y la Transparencia, entre otras instituciones actualmente agrupadas en una «Comisión Nacional para la Moralización» (2011, p.35). Este crecimiento en el número de las instituciones y de las leyes, que ha sucedido en varios países, además de suponer un enorme gasto al erario público, ha favorecido muchas veces la ralentización de los procesos de denuncia e investigación y no necesariamente la reducción de los sobornos, prevaricación, nepotismo, entre otros, en la administración pública.

Algunas medidas llevadas a cabo a partir del enfoque agente-principal han propiciado la multiplicación de instituciones de control y sanción tanto administrativas como penales (Persson et al., 2012). En su sentido más extremo, se ha promovido una especie de populismo punitivo ${ }^{7}$. A su vez, las iniciativas de transparencia se han alzado como una solución efectiva contra la corrupción hasta el punto en que muchas veces se ha equiparado

\footnotetext{
${ }^{6}$ De hecho, desde 2002, Colombia ha retrocedido 0.3 puntos en la escala de Percepción de la Corrupción de Tl.

7 Esto no quiere decir que la UNCAC haya propiciado el «populismo punitivo» en materia anticorrupción; seguramente son los altos niveles percibidos de corrupción los que propician la mayor demanda de penas más duras para los corruptos. Lo que argumentamos es que la UNCAC, o propuestas como ella, no confronta esta realidad.
} 
la transparencia con el fin de la corrupción. En palabras de Marcos Roitman, «La moderna exigencia de transparencia ha devenido en una suerte de obsesión por la misma, que sustituye la ideología y la acción política por la rendición de cuentas sobre pagos, ingresos y gastos». (Roitman, 2015). En este sentido, el «remedio de la transparencia», que en la mayoría de propuestas aparece como una de las máximas prioridades, podría empeorar la «enfermedad», ya que en contextos de corrupción generalizada donde esta sustituye a la norma formal en términos prácticos, más transparencia sólo significaría «sacar las malas prácticas y la corrupción a los balcones». Ello, probablemente, provocaría mayor sensación de corrupción por su evidente normalidad, y posiblemente alentaría a más individuos a sumarse a lo establecido, tal como apuntan Johnston (2005), Mungiu-Pippidi (2006) y Persson et al. (2013).

Por su parte, la Organización para la Cooperación y el Desarrollo Económicos (OCDE) ha elaborado Directrices para el combate contra la corrupción en multinacionales en 2003 y Códigos de ética en 2013. El Banco Mundial (BM), utilizando el mismo enfoque agente-principal, ha elaborado informes y propuestas $\mathrm{AC}$ desde que a finales de los noventas se tomara conciencia del problema (Orlando, 2004, p.657). Un ejemplo de esto es «Should Countries Care About Corruption?» (1997) producido por el BM, el cual, además, da comienzo a lo que Tesh ha llamado la «industria del desarrollo del BM» (1999); aquí se reconoce a la corrupción como uno de los principales obstáculos del desarrollo económico, sobre todo para la inversión y libertad económica de los agentes internacionales (Orlando, 2004, p.658). Recientemente, el BM ha dedicado informes a organismos concretos como el uso responsable de los productos del financiamiento para el Banco Internacional de Reconstrucción y Fomento (BIRF) o para la Asociación Internacional de Fomento (AIF) durante la preparación y/o ejecución de la financiación de importantes proyectos de inversión (Banco Mundial, 2006, p.1; 2008, p.1). Asimismo, Transparencia Internacional (TI) mediante la iniciativa Publish What You Pay y la UNODC mediante un Manual para investigadores y fiscales (2004) hacían lo propio con propuestas centradas en la transparencia y las sanciones.

A nivel internacional o intergubernamental, se puede decir que las propuestas o iniciativas del enfoque a-p no han surtido el efecto esperado 
en contextos de corrupción generalizada. Sin embargo, sus recomendaciones fueron plasmadas en políticas nacionales de muchos Estados intentando, por un lado, aumentar la transparencia en los gastos y contratos del Estado aludiendo a la «gran corrupción» (UNODC, 2004, p.27), ya que se sugiere que solo esta es combatible desde un Estado con bajos recursos y corrupción extendida, como en el caso de Perú y su Plan de Lucha contra la corrupción (CAN, 2012, p.12). Por otro lado, se intentó también reformar las leyes creando nuevos tipos penales y técnicas de investigación, cambiando la prescripción de los delitos y formulando sanciones más duras, entre otros. Este, por ejemplo, sería el caso de Brasil. Andrade señala que, desde finales de los años ochenta, este país ha aprobado gran cantidad de legislación relacionada con la transparencia y destinada al control de la administración pública en distintos aspectos con el objetivo de que exista un control efectivo de la corrupción (Andrade, 2014, p.95). También, se han tipificado nuevas conductas, eliminado indeterminaciones jurídicas que exijan alto margen de interpretación y se ha aumentado el rigor de las penas con el fin de reducir la alta impunidad existente en Brasil (Andrade, 2014, p.96).

Pese a todo ello, el nivel de percepción de la corrupción en la gran mayoría de países donde se han implementado este tipo de reformas se mantiene similar desde finales de los noventas. Perú obtiene un puntaje de 38 (sobre 100) en 2014, sin un cambio significativo desde el 2011; Brasil un 43, con un ligero retroceso desde 2012; y Colombia no registra ningún cambio desde 2005 y se mantiene en los 37 puntos en el IPC de TI. Desde otro punto de vista, las encuestas de víctimas de la corrupción llevadas a cabo en Bolivia, Mauritania, Nicaragua, Uganda, Ucrania, y Tanzania muestran que la «pequeña corrupción» y la corrupción administrativa se han mantenido por muchos años en los mismos niveles altos de corrupción; especialmente en los ámbitos de salud, educación y justicia (UNODC, 2011, p.3). Esto parece indicar que, aunque se aprueben reformas y nuevas normas formales ${ }^{8}$, las normas informales y pautas sociales que tienen mayor influencia en el comportamiento individual aún seguirán basándose en valores y principios egoístas o particularistas.

En conclusión, como se ha explicado, es razonable afirmar que en ciertos contextos existirá una falta de voluntad por parte del principal de ejercer

${ }^{8}$ No sólo AC, sino PP redistributivas en general. 
de controlador e interesado (Persson et al., 2013, p.454) porque percibe que el «particularismo» es la regla por la que se regirá el comportamiento de la mayoría, así que no se generarán unilateralmente comportamientos altruistas, cooperativos y honestos por parte de los individuos (Rothstein, 2005, p.13; Mungiu-Pippidi, 2013). Del mismo modo, es razonable argumentar que luchar efectivamente contra la corrupción en sociedades donde el particularismo o parcialidad es la norma, es como luchar por un cambio de régimen. Para Mungiu-Pippidi, esto requerirá una amplia base de participación siendo altamente improbable que suceda en un corto periodo de tiempo sin instrumentos políticos (Mungiu-Pippidi, 2011 p.112).

Las propuestas de crear sanciones más efectivas y duras, apostar por programas y plataformas online de transparencia o la construcción de más instituciones o fiscalías de control probablemente sean, en gran medida, ineficaces para prevenir que los actores participen en actividades corruptas en entornos de corrupción generalizada. Posiblemente, lo que se generará, más bien, será una ventana de oportunidad aprovechada por actores más poderosos y con intereses particularistas para castigar a un determinado funcionario, político o ciudadano, y no con el ánimo de hacer justicia en general. Así, primero, mientras que los valores predominantes en el llamado imaginario colectivo estén más relacionados con intereses particulares no habrá un cambio sustancial, no habrá acción colectiva ni habrá cambio de régimen. Son necesarios un cambio y una acción colectiva a los que parecen no haber contribuido en demasía las medidas y el enfoque a-p.

\section{La corrupción como un problema de acción colectiva}

Como acabamos de mostrar, el enfoque culturalista y el de a-p no parecen haberse ajustado a los contextos donde estaban llamados a funcionar: países con escasos recursos financieros, graves desigualdades sociales y corrupción generalizada. Por el contrario, se ha desperdiciado gran cantidad de recursos, tanto materiales como humanos, en la articulación de las medidas e iniciativas AC y se ha constituido lo que Tesh (1999) y Mungiu-Pippidi (2006) han denominado la «industria anticorrupción». 
Esta industria motivó reformas o políticas públicas anticorrupción, sobre todo en sociedades poscoloniales (Mungiu-Pippidi, 2006, p.92) o «ecosistemas» donde la corrupción es sistémica, porque es más la regla que la excepción, y generalizada, porque no se limita a ciertos sectores (Médard, 1998, p.379). Resultó muy complicado traducir las iniciativas del enfoque agente-principal en un discurso y marco teórico que confronte con la presunción de que la corrupción es un endemismo cultural propio de determinadas sociedades contra el que poco puede hacerse salvo aceptarlo (Jiménez Sánchez, 2012, p.2), tal si fuera un cáncer con el que hay que aprender a coexistir (Gil Villa, 2013). Dicho esto, no se pretende desperdiciar algunos aportes valiosos del enfoque a-p, como la relevancia del monitoreo y el castigo que funcionan para frenar la corrupción; por el contrario, lo que la corrupción como problema de acción colectiva cuestiona es la presunción subyacente de que en todas las sociedades existe un principal que quiere hacer cumplir la ley (Rothstein, 2013, p.8).

En este sentido, cabe precisar tres cuestiones: a) qué es un problema de acción colectiva; b) cuándo podemos hablar de sociedades donde la corrupción es más la norma que la excepción; y c) en qué grado el entorno determina el comportamiento humano de acuerdo a la psicología social.

\section{a) ¿Qué es un problema de acción colectiva?}

Desde que Mancur Olson publicase The Logic of Collective Action: Public Goods and the Theory of Groups en 1965, surgió un interesante debate alrededor de las acciones colectivas y la posibilidad de alcanzar resultados óptimos o benéficos para los grupos inmersos en la toma de decisiones (Ostrom, 2000, p.1). Uno de los mayores aportes al debate, por su gran carga empírica, es Governing the Commons: the evolution of institutions for collective action de E. Ostrom (1989), la cual explica la multitud de experiencias de éxito en cuanto a la gestión de recursos de uso común (en adelante RUC) a través de la acción colectiva. Ello abre la posibilidad de teorizar sobre las formas en que un grupo de personas puede alcanzar 
resultados óptimos con la inclusión de una serie de requisitos previos. Por ejemplo, descubre que, en algunas regiones costeras de la India, la autogestión de los pescadores sobre las cuotas de pesca era mucho más eficaz que en las sociedades pesqueras vecinas intervenidas por el Estado o una institución privada. De aquí se desprende que lo común tiende a estar mejor gestionado dentro de un marco normativo propicio para la acción colectiva (en adelante MNAC), el cual envuelve siete elementos fundamentales para la acción colectiva, entre ellos la confianza y el largoplacismo en los beneficios (Ostrom, 1989). Esta evidencia empírica, y la intención de construir un marco referencial para la gestión de los RUC sin miedo a complejizar los modelos sobre el comportamiento humano, impulsó otros estudios y la construcción de marcos teóricos en los cuales el ser humano se comportará según multitud de coyunturas (no solo como un ser racional y egoísta). La teoría de la acción colectiva, explicada a través de numerosas experiencias alrededor del mundo, contradice los modelos clásicos de comportamiento humano a la hora de afrontar la gestión sostenible de los RUC cuyos participantes eran siempre representados atrapados en situaciones como el dilema del prisionero y otros dilemas sociales en los que carecen de capacidades para cambiar la estructura del juego por sí mismo, como por ejemplo la comunicación entre ellos (Ostrom, 2014 [2009], p.20).

En los casos de acción colectiva con éxito, la mayoría de ellos en grupos pequeños, existe un alto de grado de comunicación entre los participantes a través de la cual se trazan varios acuerdos altamente consensuados, por ejemplo sobre las sanciones en caso de bajo rendimiento o un bajo input, que no siempre serán ex-post (Ostrom, 2009, p.37). Es más, Ostrom se refería al modelo de rational choice como uno que no refleja la complejidad del comportamiento humano (20014, p.18), pues el sujeto, primero, no es solo individuo, sino también comunidad (la felicidad y bienestar están ligados a su entorno social, medioambiental, Estado, etc.); segundo, las personas responden según el contexto e incluso el estado de ánimo; $\mathrm{y}$, tercero, el ser humano puede y va a comportarse según el bien que esté en juego (Ostrom, 2014[2000], p.22), por lo que bienes como la paz, seguridad, o incluso lagos, bosques y sistemas de irrigación demandarán un tipo de gestión y comportamiento por parte del «consumidor» totalmente distinto a los bienes privados o bienes tarifa (ver cuadro 1), rompiendo parcialmente con el determinismo racionalista de 
algunos teóricos sobre el comportamiento humano.

Cuadro 1. Los cuatro tipos de bienes según Ostrom. Fuente: Ostrom (1990).

En resumen, en este marco normativo, aunque no es el único elemento importante para la acción colectiva, el elemento central e interrelacionado en todos los niveles y etapas de la acción colectiva es la confianza entre los participantes (Ostrom, 2014 [2009], p.48), determinado a su vez por la acumulación de experiencias anteriores y el grado de comunicación y transparencia entre los actores. Así, un problema de acción colectiva es uno en el cual nadie o solo algunas excepciones cooperan porque desconfían de que los demás lo vayan a hacer. La acción colectiva no es posible sin confianza. Corromper o dejarse corromper debería estar asociado con la confianza que se tenga en los demás. En contextos donde la corrupción fuera percibida como la norma o el comportamiento esperado, se argumenta que la corrupción es un problema de acción colectiva porque se desconfía ${ }^{9}$ del otro en cuanto a que vaya a ser

Sustractabilidad de uso

\begin{tabular}{l|l|l|l|}
\cline { 2 - 4 } & & Alta & Baja \\
\cline { 2 - 4 } $\begin{array}{l}\text { Dificultad } \\
\text { de excluir } \\
\text { beneficiarios } \\
\text { potenciales }\end{array}$ & $\begin{array}{l}\text { RUc: cuencas hidro- } \\
\text { lógicas, lagos, siste- } \\
\text { mas de irrigación, } \\
\text { pesquerías, bosques, } \\
\text { etc. }\end{array}$ & $\begin{array}{l}\text { Bienes públicos: paz, seguridad de } \\
\text { una comunidad, defensa nacional, } \\
\text { conocimiento, protección contra } \\
\text { incendios, pronósticos del tiempo, } \\
\text { etc. }\end{array}$ \\
\cline { 2 - 4 } & Baja & $\begin{array}{l}\text { Bienes privados: } \\
\text { comida, ropa, auto- } \\
\text { móviles, etc. }\end{array}$ & $\begin{array}{l}\text { Bienes tarifa: cines, clubes } \\
\text { privados, guarderías, etc. }\end{array}$ \\
\hline
\end{tabular}

«limpio», ya que existe falta de comunicación y de experiencias acumuladas. En otras palabras, ¿por qué mantenerse limpio si todo el mundo parece corrupto?

Si decimos que la corrupción es un problema de acción colectiva, la confianza será, en un alto nivel, la antítesis de la corrupción. Por lo tanto, a mayor confianza interpersonal, menor grado de corrupción. Dos de los principales aportes empíricos en este punto son los de Uslaner (2008) y Rothstein (2005). Este último, comprueba que, en los países europeos, a mayor confianza interpersonal, menor IPC. Mientras que el primero argumenta que «Las raíces de la corrupción descansan sobre la desigualdad económica y menor confianza en gente distinta a ti

9 La confianza es señalada por varios autores como uno de los elementos básicos para empezar un proceso de acción colectiva y romper cualquier trampa social (Putnam, 1993; Rothstein, 2005:67; Herreros y Criado, 2006). En un plano económico, ha sido denominado por Robinson y Acemoglu como círculo vicioso. 
(étnicamente) y que la propia corrupción produce desconfianza generalizada y desigualdad» $(2008$, p.4); para apoyar su tesis, encuentra una correlación bastante pronunciada entre confianza e IPC.

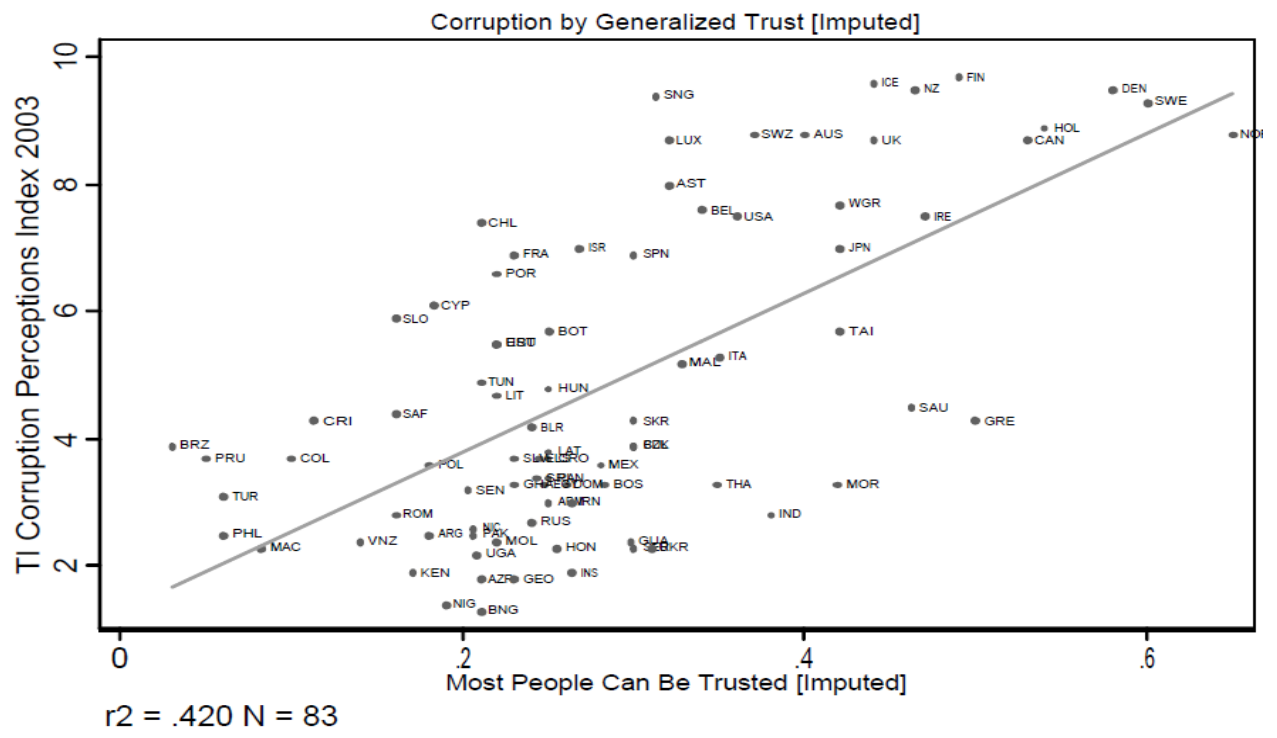

Gráfico 1. Correlación entre confianza generalizada (WVS) y corrupción (TI). Fuente: Uslaner, 2008

Aunque en este gráfico se observen excepciones, como Grecia o Arabia Saudita, en el sentido de que a pesar de que una buena parte de individuos creen que el resto de miembros de su sociedad son confiables, los niveles de percepción de la corrupción se mantienen altos. $\mathrm{O}$ en el caso contrario, sociedades con bajos niveles de confianza interpersonal y con niveles de percepción de la corrupción corresponden a valores medios, como Eslovenia o Chile ${ }^{10}$. Aun así, en general, la «confianza interpersonal» y la «corrupción pública» percibida parecen ser, y ratificando nuestra primera hipótesis, polos opuestos. Mayores niveles de corrupción percibida están significativamente asociados con bajos niveles de confianza y vice versa ( $\mathrm{r} 2=0.420)$. Y es más evidente aún en tres de los países menos corruptos del mundo según el IPC de TI: Dinamarca, Suecia y Canadá, donde cerca del 60 por ciento de la gente cree que la mayoría del resto de la sociedad puede ser confiable; mientras que en Brasil, Filipinas y Turquía solo un

10 A pesar de que estos países hayan alcanzado bajos niveles de corrupción, parece que esto no pasó precisamente por romper con la confianza particularizada ni por generar confianza interpersonal generalizada. 
10 por ciento confía en los demás, puntuando estos entre 2 y 4 en el IPC.

En sociedades con mayor percepción de corrupción, señala MungiuPippidi, no habría tradición de asociación entre iguales, ya que la confianza es particularista y se basa en clanes, mecenas y clientes (2013, p.108) así que será más conveniente intentar acceder al grupo privilegiado al convertirse en clientes o a través de las influencias, en lugar de participar en una dura batalla a largo plazo para cambiar las reglas del juego hacia un universalismo ético que produciría que los clientes del orden existente (más numerosos, más ricos, y mejor posicionados en la sociedad) probablemente luchen contra tal progreso $(2013$, p. 109).

\section{b) ¿Cuándo podemos decir que en una sociedad la corrupción es más la regla que la excepción?}

Para esto, lo primero que nos preguntamos, como hizo Mungiu-Pippidi, es si estamos tratando con la corrupción moderna donde esta es la excepción a unas normas imparciales y universales o estamos tratando con un particularismo y una cultura del privilegio donde la corrupción en sí misma es la norma. O más bien, ¿estamos tratando con una combinación de las dos como es el caso de las sociedades poscoloniales?

Este punto es uno de los más controvertidos de nuestro trabajo ya que las definiciones sobre corrupción endémica o sistémica ${ }^{11}$ no delimitan «científicamente» qué sociedades están dentro y cuáles fuera de esta categoría. Nosotros, a diferencia de autores como Rothstein y Holmberg que aseguran que la vasta mayoría de pueblos del mundo se encuentra

\footnotetext{
11 Incluso la definición que usa Rothstein de «más la regla que la excepción» es bastante inexacta cuantitativamente. Para sostener su argumento utiliza entrevistas a periodistas ugandeses y keniatas para hacer ver que efectivamente, el acto corrupto es, como bien señala Médard, sistémico, porque es más la regla que la excepción, y generalizado, porque no se limita a ciertos sectores (Médard, 1998, p.379).
} 
sumida bajo administraciones públicas profundamente corruptas (2012), argumentamos que hay correspondencia entre los Estados poscoloniales y altos niveles de percepción de la corrupción según $\mathrm{TI}^{12}$.

De forma general, Mungiu-Pippidi afirma que el particularismo como norma incluye a las democracias delegativas latinoamericanas, anarquías competitivas africanas y democracias electorales postcomunistas, y que, si existe un elemento en común, este es la combinación de corrupción premoderna y corrupción moderna, o más bien del viejo particularismo y la nueva corrupción (2006, p.90). De forma más particular, Johnston pone algunos ejemplos a través de lo que llama «Oligarchs and Clans»" ${ }^{13}$ (México, Rusia y Filipinas son sus ejemplos) donde existirían muchas de las condiciones para empezar a hablar de «corrupción más como regla que como excepción». Lo que este grupo de países tienen en común y, a su vez, los diferencia de lo que el mismo autor llamó los «Official Moguls» (China, Kenia e Indonesia son sus ejemplos esta vez) es que, a pesar de que también esté claro quién gobierna, el poder oficial está integrado en la corrupción -y no comprometido por ella- y en los cuales, los corruptos actúan casi con total impunidad (Johnston, 2005, p.154), con lo que en este grupo sería probablemente más difícil salir de la trampa política que en los «Oligarchs and Clans» debido a una noción difusa entre lo privado y lo público ${ }^{14}$.

De este modo, este tipo de fenómenos se estaría reproduciendo en buena parte de las administraciones del África subsahariana (Médard, 1998; Robinson \& Acemoglu, 2012; Persson et. al, 2013), lo que algunos han llamado incluso regímenes cleptocráticos (Senior, 2006) o cultura de la corrupción (Smith, 2007) refiriéndose concretamente al Congo y Nigeria de los noventas y 2000 respectivamente. La corrupción sistémica también se estaría dando en América Latina, especialmente en relación a la gestión

\footnotetext{
12 A pesar de que autores como Johnston (2005) tiene sus reservas, tanto Uslaner (2008) como Rothstein (2011), entre otros, consideran al IPC de TI como una forma «aproximadamente cierta» de medir el nivel de corrupción política en un país.

13 Para Johnsto,n la transparencia, privatización, racionalización de las funciones públicas y aseverar el cumplimiento de la ley son buenas ideas, pero asumen la existencia de un Estado lo suficientemente fuerte para realizar sus funciones básicas y otorgar incentivos a largo plazo para hacer eso. Asimismo, instar a la sociedad civil a la movilización contra la corrupción tiene poco sentido cuando la confianza es débil y la seguridad, factor no muy tomado en cuenta, es un factor de vida primordial (Jhonston, 2005, p.153).

14 En este punto es valioso recordar lo que decía Philp respecto a que precisamente la noción mainstream de corrupción descansa sobre los valores occidentales, unos valores que se conocen tal vez, pero no se promueven -ni tendrían por qué- o se practican en todo el mundo.
} 
y explotación de los recursos naturales, o en los países que integraron la Unión Soviética en materia de privatización de empresas o sociedades públicas (Rose-Ackerman, 1999, p.60). Aunque también hay autores que han utilizado esta categoría para analizar la corrupción a nivel local ${ }^{15}$. Uno de ellos es Uslaner cuando se refiere a la ciudad de Paterson en Nueva Jersey (Uslaner, 200, p.:4), o autores españoles cuando analizan el caso de la corrupción urbanística en Lanzarote y su relación con la falta de confianza en las instituciones (García-Quesada et al., 2014, p.17) en un Estado donde no existe corrupción sistémica como tal (Jiménez, 2015).

En el siguiente cuadro se observa la evolución del nivel de percepción de la corrupción de TI de algunos de los países a los que la literatura, y este estudio, hacen referencia para hablar del «fracaso» de las reformas AC cuando se tiene corrupción generalizada o existe una «trampa social». De este modo, es evidente que en estos Estados no ha habido un progreso o cambio sustancial en el IPC en el periodo 1995-2013:

$15 \mathrm{~F}$. Jiménez sugiere que en Lanzarote, durante la década de los 90, existió una corrupción sistémica en el terreno de la recalificación. 


$\begin{array}{lccccccccccc}\text { IPC de TI } & 1995 & 1997 & 1998 & 1999 & 2001 & 2003 & 2005 & 2007 & 2009 & 2011 & 2013 \\ \text { Brasil } & 2.70 & 3.56 & 4.0 & 4.1 & 4.0 & 3.9 & 3.7 & 4.0 & 4.3 & 4.2 & 4.3 \\ \text { Colombia } & 3.44 & 2.23 & 2.2 & 2.9 & 3.8 & 3.7 & 4.0 & 3.8 & 3.5 & 3.6 & 3.6 \\ \text { Filipinas } & 2.77 & 3.05 & 3.3 & 3.6 & 2.9 & 2.5 & 2.5 & 3.0 & 3.4 & 3.6 & 3.8 \\ \text { Kenia } & & & & & & & & & & & \\ \text { México } & 3.18 & 2.66 & 3.3 & 3.4 & 3.7 & 3.6 & 3.5 & 3.3 & 3.4 & 3.4 & 3.5 \\ \text { Nigeria } & & 1.76 & 1.9 & 1.6 & 1.0 & 1.4 & 1.9 & 2.3 & 2.7 & 2.5 & 2.7 \\ \text { Perú } & & & 4.5 & 4.5 & 4.1 & 3.7 & 3.5 & & & & 3.8 \\ \text { Rumanía } & & 3.44 & 3.0 & 3.3 & 2.8 & 2.8 & 3.0 & 3.5 & 4.4 & 4.3 & 4.3 \\ & & & & & & & & & & & \\ \text { Rusia } & 2.27 & 2.4 & 2.4 & 2.3 & 2.7 & 2.4 & 2.5 & 2.6 & 2.8 & 2.7 \\ \text { Uganda } & & 2.6 & 2.2 & 1.9 & 2.2 & 2.5 & 2.5 & 2.5 & 2.6 & 2.9 \\ \text { Zambia } & & & 3.5 & 3.5 & 2.6 & 2.5 & 2.6 & 3.0 & 3.5 & 3.7 & 3.8\end{array}$

Cuadro 2. Evolución del nivel de percepción de la corrupción (1995-2013). Elaboración propia en base a datos de Transparencia Internacional.

Siguiendo la lógica de corrupción como problema de acción colectiva, se ha utilizado la plataforma de la Encuesta Mundial de Valores ${ }^{16}$ acerca de la confianza que los más de 13000 encuestados muestran a sus compatriotas en general (ver gráficos 2 y 3). Así, podemos comprobar de manera preliminar que existe una tendencia: en los países donde la confianza es baja y no aumenta, los niveles de corrupción parecen mantenerse altos y no reducirse. $\mathrm{O}$, de manera contraria, en la cual la corrupción se mantiene alta, los niveles de confianza interpersonal se muestran bajos, aunque cabe precisar que existen excepciones, por ejemplo, a pesar de que Perú $(6,2)$ y México $(15,4)$ tienen niveles relativamente dispares de confianza generalizada en 2005-2009, poseen idénticos niveles en el IPC (3,5 en 2005 y 3,3 en 2006). Este análisis de países se verá complementado con la correlación que elabora Uslaner en 2008 en un estudio transnacional en el que toma en cuenta una muestra de

\footnotetext{
${ }^{16}$ Disponible en: http://www.worldvaluessurvey.org/WVSOnline.jsp Último acceso: 26/05/15.
} 
83 Estados (ver gráfico 1).

\begin{tabular}{|c|c|c|c|c|c|c|c|c|c|}
\hline \multicolumn{10}{|c|}{ Trust in people } \\
\hline & \multirow{2}{*}{ TOTAL } & \multicolumn{8}{|c|}{ Country } \\
\hline & & Colombia & South Korea & Mexico & Nigeria & $P_{\text {enu }}$ & Philippines & Romania & Rusaia \\
\hline Most people can be trusted & 16.6 & 10.3 & 30.3 & 26.4 & 16.4 & 4.9 & 5.5 & 17.9 & 23.2 \\
\hline Can't be too careful & 80.2 & 88.6 & 69.6 & 67.6 & 76.0 & 922 & 93.8 & 77.9 & 73.8 \\
\hline NA & 1.1 & - & - & - & 7.4 & - & - & - & - \\
\hline DK & 2.1 & 1.1 & 0.2 & 6.0 & 0.2 & 2.9 & 0.8 & 4.2 & 2.9 \\
\hline (N) & $(13,474)$ & $(3,029)$ & $(1,249)$ & $(1,510)$ & $(1,996)$ & $(1,211)$ & $(1,200)$ & $(1,239)$ & $(2,040)$ \\
\hline
\end{tabular}

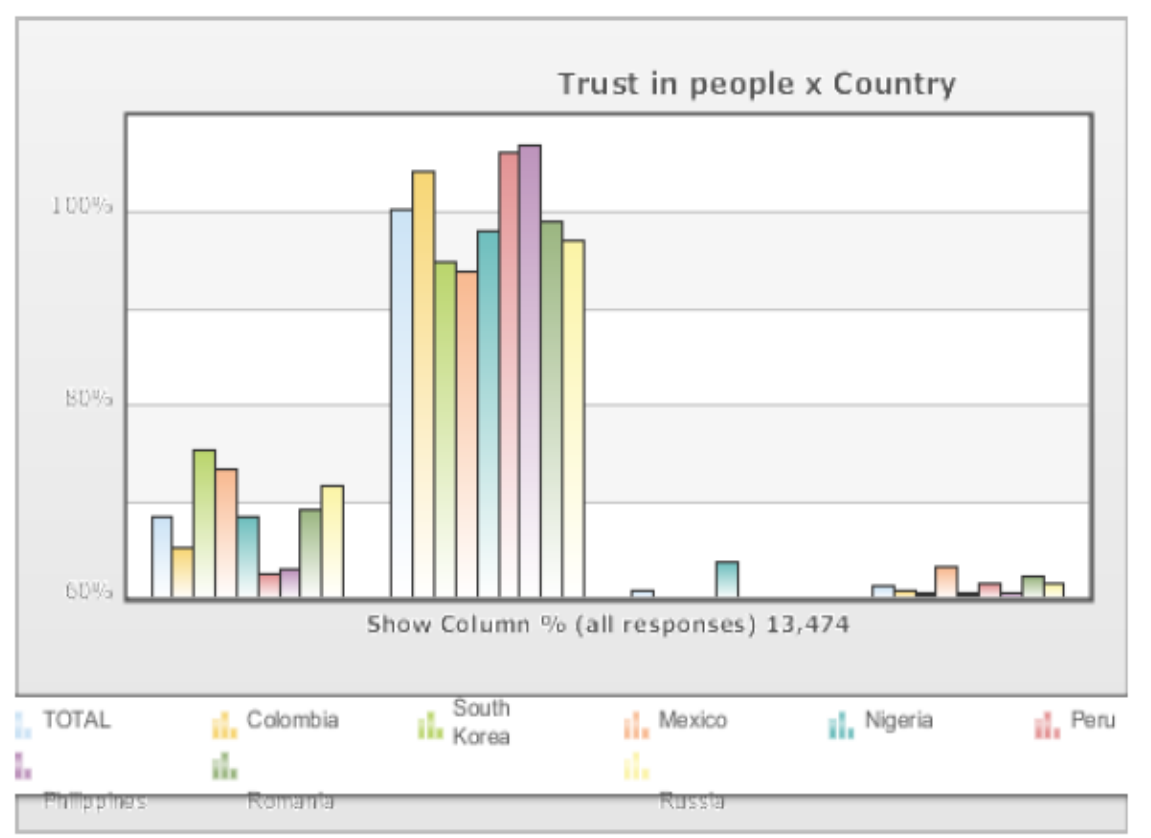

Gráfico 2: Confianza generalizada según país. Países y años seleccionados: Colombia 1997, México 1996, Nigeria 1995, Perú 1996, Filipinas 1996, Rumanía 1998, Rusia 1995, Corea del Sur 1996. Fuente: Encuesta Mundial de Valores (Tercera Ola). 


\begin{tabular}{|c|c|c|c|c|c|c|c|c|}
\hline \multicolumn{9}{|c|}{ Most people can be trusted } \\
\hline & \multirow[b]{2}{*}{ TOTAL } & \multicolumn{7}{|c|}{ Country/Region } \\
\hline & & Brazil & Colombia & $\begin{array}{l}\text { South } \\
\text { Korea }\end{array}$ & Mexico & Paru & Romania & Zambia \\
\hline Nost people can be trusted & 14.5 & 9.2 & 14.3 & 28.0 & 15.4 & 6.2 & 19.3 & 10.8 \\
\hline Need to be very careful & 83.2 & 89.2 & 84.6 & 71.1 & 83.8 & 92.4 & 75.6 & 82.7 \\
\hline Missing; Not asked by the interviewer & + & - & - & - & - & - & - & 0.1 \\
\hline No answer & 1.1 & 1.5 & $\cdot$ & 0.9 & 0.3 & 1.4 & 2.1 & 2.1 \\
\hline Don'tknow & 1.3 & - & 1.1 & - & 0.4 & - & 3.0 & 4.3 \\
\hline (N) & $(12,061)$ & $(1,500)$ & $(3,025)$ & $(1,200)$ & $(1,560)$ & $(1,500)$ & $(1,776)$ & $(1,500)$ \\
\hline
\end{tabular}

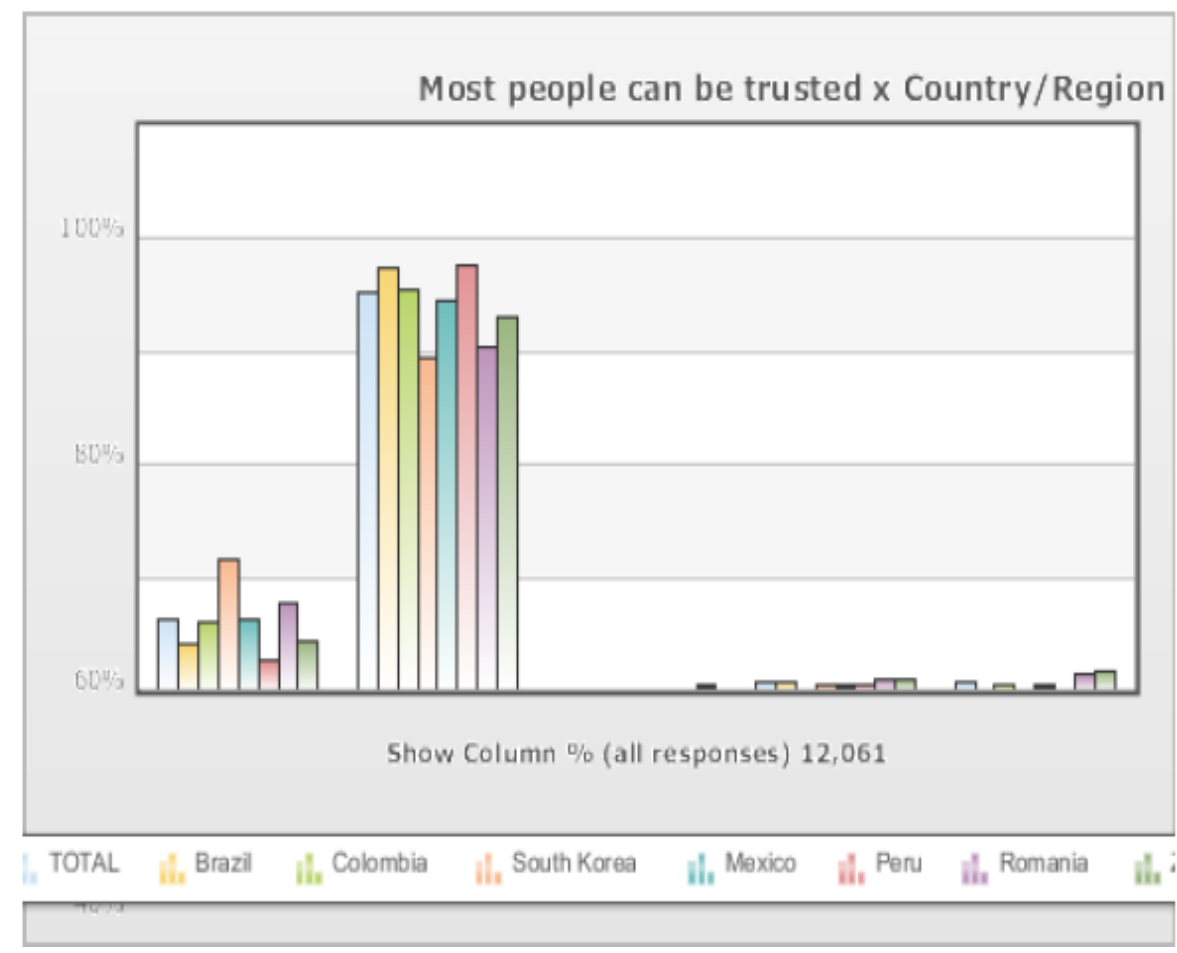

Gráfico 3: Confianza generalizada según país. Países y años seleccionados: Brasil 2006, Colombia 2005, México 2005, Perú 2006, Rumanía 2005, Corea del Sur 2005 y Zambia 2007. Fuente: Encuesta Mundial de Valores (Quinta Ola).

La Encuesta Mundial de Valores, en lo que respecta a la «confianza interpersonal», en lugar de hacer referencia a la simple y arriesgada afirmación de «sí» o «no» confió, trata de que el entrevistado genere su respuesta a través de unos cálculo, inconscientes- individuales en los que la experiencia previa. La idea de compartir unos valores o incluso la efectividad del Estado de Derecho influyen; ello da como resultado la creencia afirmativa o negativa de que «En general hallo, o no, confiables 
al resto de individuos de mi comunidad o sociedad» (Rothstein 2005, p.126).

En este punto, no son pocos los que sostienen que la interacción con el Estado influye en el desarrollo de confianza interpersonal. Concretamente, Estados más eficaces y neutrales garantizan el cumplimiento de acuerdos privados fomentando el desarrollo de confianza entre los ciudadanos (Herreros y Criado, 2006, p.44) e, incluso, señalan Rothstein y Stolle que «tener, desde joven, una cierta tendencia a confiar puede ser el resultado de la influencia que tuvieron en los padres las experiencias con ciertas instituciones» (2008). Así, la tendencia de uno a confiar en el otro puede estar predeterminada por la confianza que tiene uno en las instituciones, lo que, a su vez, es el resultado de la calidad experimentada en las interacciones con las mismas.

Rothstein y Stolle argumentan que históricamente no se han hecho grandes descubrimientos en torno a los mecanismos causales entre confianza interpersonal generalizada y «confianza en el gobierno» porque no se han distinguido entre diferentes tipos de instituciones (2008). De este modo, al asociar «confianza en el gobierno» con confianza generalizada, tradicionalmente los resultados han sido mixtos. Su idea fuerte es: lo que en mayor medida marcará el grado de confianza de los individuos vendrá dado principalmente por el grado de buenas o malas experiencias que han tenido los ciudadanos con ciertas instituciones cotidianas (2008), ya que éstas determinan construyen en mayor grado los «mapas cognitivos» que se forman mediante la interacción de las instituciones a lo largo del tiempo. Cuanto mejor se cumplan las expectativas $^{17}$ sobre las instituciones cotidianas ${ }^{18}$, mayor será la confianza el Estado, sugiere Rothstein. Las instituciones cotidianas son la policía, los tribunales o los colegios públicos y ejercen una gran influencia en la configuración de imaginarios sobre el Estado y su nivel de corrupción.

\footnotetext{
${ }^{17}$ Rothstein y Stolle argumentan que los ciudadanos en los Estados de Derecho de estructuración weberiana tienen diferentes expectativas según el tipo de instituciones. Así, de las instituciones de gobierno se esperan comportamientos ideológico-políticos; de las burocráticas, comportamientos imparcial-administrativos; y de las sociales comportamientos mercantilistas-sectorizados, respetando todas ellas la legalidad. En una democracia, la confianza en las instituciones vendrá determinada por la coincidencia entre las expectativas que los ciudadanos tengan sobre ellas deberían hacer, y lo que hacen en la realidad (2008).

${ }^{18}$ Traducción de lo que Rothstein y Stolle llaman day-a-day institutions (2007).
} 


\section{c) En qué grado el entorno determina el comportamiento humano de acuerdo a la psicología social}

¿Es posible que un grupo de individuos se asocien para promover la ética universal en lugar del egoísmo e individualismo? Esto es lo que según Mungiu-Pippidi preguntaría un psicólogo social (2013, p.109). La «trampa social» también puede ser observada desde otra perspectiva.

Stanley Milgram apunta, tomando como referencia los «experimentos de laboratorio» que E. Asch llevó a cabo respecto a la presión social sobre el individuo, que, en un altísimo porcentaje, las pautas de comportamiento del grupo marcarán la del individuo, aun cuando este tenga unas convicciones contrarias a las que sugiere la pauta grupal y pretenda mantenerlas (Milgram, 1992, p.197). El ser humano tiende a adaptarse mientras aquello no le conlleve un claro perjuicio. Por tanto, como ser racional pero también social, el individuo varía considerablemente (con mayor frecuencia de lo que cabría imaginar) su comportamiento (aunque no siempre su actitud) dependiendo del grupo o sociedad en que se encuentra. Stanley Milgram sostiene que usualmente no es el carácter de una persona lo que determina sus acciones, sino la situación en la que se encuentra, señalando que cada participante en un grupo es un individuo complejo con propósitos y motivaciones por sí mismo; aun así, el grupo cumple su función modificando con bastante éxito su comportamiento, incluso con una cierta armonía en el sentido de que se parecerá bastante a lo que los demás hacen (Milgram, 1992, p.199).

Esto también se pudo constatar con los experimentos de la cárcel de Stanford llevados a cabo por el mismo Milgram en 1971. Por otra parte, sus experimentos sobre obediencia a la autoridad estarían muy relacionados con aquellos sobre la presión colectiva de Asch, ya que, según el propio Milgram, en estos se sustituiría la acción-consecuencia de la autoridad por el juicio gestual (susurros, miradas, llamadas de atención) del grupo que hace cambiar el comportamiento del individuo, y en lugar de que este relacione la autoridad solo con un individuo, la autoridad «inquebrantable» es ejercida por la presión social.

En opinión de Milgram, los experimentos de Asch favorecen la hipótesis 
de que la influencia del grupo puede moldear el comportamiento en un tiempo tan corto y con tal efectividad que sería casi imposible hacerlo sin dicha influencia colectiva tanto en un sentido negativo (1971, p.196) como positivo (1971, p.232). Además, a pesar de que los eventuales efectos de la presión social estén claramente establecidos (por una comparación de las condiciones experimentales y de control), los efectos ocurren solo en un contexto donde existe una potencial sanción autoritaria, es decir, en la medida en que nosotros observemos a ese grupo como autoridad (y sus efectos como sanciones) y no como terceros individuos ajenos, mayor será la probabilidad de «obedecer» (Milgram, 1992 [1977], p.219).

Este marco interpretativo se ajusta de manera más precisa, por ejemplo, a una oficina local de un tribunal de cuentas, a un departamento de cierto ministerio o a la planilla de un gobierno local que al conjunto de una sociedad. Pero no deja de ser útil para apoyar las tesis de «corrupción como problema de acción colectiva» en cuanto a por qué al individuo le es tan difícil cooperar. Aplicar la teoría de Milgram en un grupo reducido de personas aporta más claves acerca de por qué las personas se adaptan casi siempre al contexto. Asimismo, desde estos experimentos se sugiere que romper el círculo vicioso de la corrupción es mucho más difícil de lo que pueda parecer; sin embargo, también favorece la idea de que una vez comenzado o instaurado un círculo virtuoso en el que la confianza y la cooperación sean el valor y comportamiento predominantes será muy difícil romperlo ya que el individuo se adaptará y cooperará en lugar de salirse de la norma.

Comprobamos que el enfoque de acción colectiva no solo halla la falta de confianza interpersonal como mayor causa del problema e identifica una «trampa social» (consecuencia de la falta de cooperación) en la que se encuentran sumidas algunas sociedades, sino que también confirma la necesidad de articular otro tipo de iniciativas AC que intenten revertir la desconfianza y la falta de cooperación. De este modo, en lugar de ir únicamente orientadas a combatir la corrupción, deberían tratarse de medidas «anti-trampa social» o «pro-confianza generalizada» que busquen aumentar tanto la confianza interpersonal como la confianza hacia las instituciones. El enfoque a-p, en este sentido, no es despreciable, ya que contribuye a entender mejor el comportamiento de los agentes en un nivel micro en ciertos contextos de organización jerárquica (2015, 
p.11), mientras que el enfoque de «problema de acción colectiva» nos ayuda a entender mejor el comportamiento tanto del principal como del agente en cuanto que aporta el factor «social o entorno» (premisa de la Psicología Social también) en la motivación de dicho comportamiento.

Finalmente, en este punto es pertinente recordar que, como Ostrom (2014 [1998]) y Rothstein (2005) consideran, el ser humano no se ve únicamente como individuo ni únicamente opera como un ser racional, por lo que el problema de la falta de cooperación no puede ser únicamente solucionado dentro del enfoque racionalista ni mucho menos dentro del culturalista, ya que ambas perspectivas asumen los fundamentos básicos que guían al individuo en su comportamiento (Rothstein, 2005, p.29), y segundo, ambos enfoques están orientados hacia razonamientos y discursos deterministas.

\section{Conclusiones}

Las evidencias aquí presentadas apuntan a que las leyes que promueven sanciones más duras a los corruptos no hacen que los potenciales funcionarios corruptos dejen de «insinuarse» o pedir directamente una coima, por lo que seguirá siendo muy difícil denunciar. La aprobación de 
una licencia o trámite suele estar condicionada al pago de una coima. Todo el mundo sabe que tiene que pagar para obtenerla, y todo el mundo sabe que, si denuncia la corrupción, tendrá que pagar también una coima para que la denuncia llegue a buen puerto.

Es esta la realidad que se reproduce todos los días. El modelo agenteprincipal asume la existencia de un principal interesado en luchar contra la corrupción, lo cual en la región latinoamericana es especialmente cuestionable. En contextos donde la corrupción es más la regla que la excepción es ilógico pensar que habrá una fuerza interesada en monitorear, denunciar y sancionar y/o hacer política de manera distinta.

El enfoque de acción colectiva evidencia que altos niveles de confianza se asocian de manera significativa con bajos niveles de corrupción y que, si pensamos cómo incrementar la confianza desde el Estado, es menester reintroducir en el centro de la reforma a las instituciones cotidianas. Son estas las que influyen a mayor medida en la configuración de imaginarios sobre «el otro», lo cual es clave para intentar revertir la trampa política en la que algunas sociedades, donde la corrupción es más la regla que la excepción, se encuentran estancadas.

No obstante, estamos de acuerdo con Marquette y Peineff, quienes indican que, en una dimensión de reformas y soluciones, la supervisión, la transparencia y las sanciones, son variables que también importan, especialmente, deducimos, la primera vez que un individuo decide racionalmente corromperse. Creemos que los dos enfoques teóricos en conjunto enseñan que la corrupción persiste en países con bajos niveles de confianza debido a que no solo es difícil controlar al agente y denunciarlo cuando actúa en contra de nuestros intereses (aporte del agente-principal), sino también debido a que no existen los incentivos necesarios («no coopero porque no confío») para emprender estas acciones (aporte de la teoría de la acción colectiva).

Apoyarnos en la psicología social y los experimentos citados ha reforzado la idea de que el entorno determina el comportamiento humano sobremanera. Sabemos, pues, que el ser humano no se considera únicamente como individuo ni únicamente opera como un ser racional, sino que responde a identidades y se auto-reconoce como parte de grupos; 
uno de ellos es de la nación. El relato oficial del « ¿cómo somos? » y la rememoración constante de que «el otro no es tan malo como parece» y que «el otro podría fácilmente denunciarte si te corrompes» puede repercutir en la probabilidad de iniciar una actividad corrupta.

En otras palabras, se puede decir que la corrupción consiste, allí donde el comportamiento arbitrario, individualista y egoísta es el esperado por la mayoría, en un problema de acción colectiva (Mungiu-Pippidi, 2006; Persson et al., 2013; Jiménez 2014; Marquette y Peiffer 2015) y que lo más importante en estas situaciones es conseguir que las instituciones con las que uno más suele interactuar sean imparciales, puesto que estas tendrán un mayor impacto en la generación de confianza interpersonal y en la configuración de imaginarios sobre el Estado.

Las buenas instituciones logran que paulatinamente se confie en ellas y en los demás, afectando notablemente el aumento de la cooperación y, por ende, reduciendo la corrupción a todos los niveles del Estado ${ }^{19}$; es decir, las instituciones cotidianas pueden impulsar la formación de un principa ${ }^{20}$ (la sociedad civil) que confíe en que, por lo menos, la policía y la justicia harán su trabajo, y que ello repercutirá en los demás.

Se sugiere profundizar en las características de las instituciones cotidianas que hace falta reformar en cada Estado de América Latina para mejorar, en cada nivel estatal, el grado de satisfacción de los ciudadanos en su interacción con el mismo. Aunque en el presente artículo se manifiestan unas pautas para la región, se recomienda aplicar las sugerencias teniendo en cuenta el contexto social, la cultura política, y la calidad y fortaleza de las instituciones país por país.

\section{Bibliografía}

Acemoglu, D., \& Robinson, J. (2009). Economic Origins of Dictatorship and Democracy. Cambridge. https://doi.org/10.1017/CBO9780511510809

(2012). Por qué fracasan los países: Los orígenes del poder, la prosperidad y la pobreza. $1^{\mathrm{a}}$ ed. Barcelona:

\footnotetext{
19 Esta es, en esencia, la lógica que emplean Uslaner (2008) y Rothstein y Stolle (2008). Es bidireccional (de ida y vuelta).

20 Como la propia teoría de agente-principal señala, es necesaria la existencia de un principal activo e interesado en la accountability, denuncia y sanción, si cabe.
} 
Deusto.

Banco Mundial (2018) Woldwide Governance Indicators http://info.worldbank.org/governance/wgi/index.aspx\#reports

Banco Mundial (2006). On Preventing and Combating Fraud and Corruption in Projects Financed by IBRD Loans and IDA Credits and Grants. Recuperado de http://siteresources.worldbank.org/INTOFFEVASUS/Resources/ WB_Anti_Corruption__ Guidelines_10_2006.pdf

Bardhan, P. (1997). Corruption and Development: A Review of Issues. Journal of Economic Literature, 35(3) 1320-1346.

Chayes, S. (2015). Thieves of State: Why Corruption Threatens Global Security. Nueva York.

Comisión de Alto Nivel Anticorrupción. (9 de diciembre de 2012). Plan Nacional Anticorrupción 2012-2016. [Decreto Supremo No119-2012-PCM] Recuperado de http://www.pcm.gob.pe/normaslegales /2012/DS-119-2012-PCM.pdf

Dahlström, C., Lapuente, V., \&Teorell, J. (2009). Bureaucracy, Politics and Corruption. En The Quality of Government Institute. Gothenburg.

Gil Villa, F. (2008). La Cultura de la Corrupción. En A. Heidenheimer, \& M. Johnston (Eds.), Political corruption: concepts \& contexts. New Jersey: Transaction Publishers.

Gil Villa, F. (2013). Los Discursos sobre Corrupción en México. Revista Sociedad \& Equidad, (5)259-275. https://doi.org/10.5354/0718$\underline{9990.2013 .26320}$

Holmberg, S., \& Rothstein, B. (2012). Good Government: The Relevance of Political Science. Reino Unido: Edward Elgar Publishing Ltd. https://doi.org/10.4337/9780857934932

Huntington, S. (1968). El orden político en las sociedades en cambio. Buenos Aires: Editorial Paidos.

Inglehart, R. (1997). Modernization and Postmodernization: Cultural, Economic and Political Change in 43 Societies. Princeton: 
Princeton University Press.

Jiménez Sánchez, F. (2014). La trampa política: la corrupción como problema de acción colectiva. En E. Pastor, G. Tamez Gonzáles, K. Annett, \& C. Sáenz López (Eds.), Gobernabilidad, ciudadanía y democracia participativa: análisis comparado España-México (pp.157-174). Madrid: Dykinson, 2014.

Johnston, M. (2005). Syndromes of Corruption: Wealth, Power, and Democracy. Cambridge: University Press. https://doi.org/10.1017/CBO9780511490965

Kafka, F. (1925). The trial (p.55). [Trad. David Wyllie]. Recuperado de https://www.planetebook.com/free-ebooks/the-trial.pdf [Consulta de 28 de octubre de 2018]

(2010). El proceso. De Bolsillo

Klitgaard, R.E. (1988). Controlling corruption. Berkeley: University of California Press.

La Porta, R., Lopez-de-Silanes, F., Shleifer, A., Vishny, R.W. (1997). Trust in Large Organizations. The American Economic Review, Papers and Proceedings, 87(2) 333-38

(1999). The quality of government. Journal of Economics, Law and Organization, 15 (1), 222-279. https://doi.org/10.1093/jleo/15.1.222

Lozano, M.B., Hidalgo, A., \& Pindado García, J. (2003). El Conflicto Accionista-Directivo: Problemas y Propuestas de Solución. Tribuna de Economía, (813) 225-245.

Malinowski, B. (1926). Crimen y costumbre en la sociedad salvaje (pp. 32-59). Ed. de 1986. Planeta De Agostini.

Marquette, H., \&Peiffer, C. (2015). Corruption and Collective action. DLP Research Paper 32. Developmental Leadership Program.

Marquette, Heather \&Peiffer, Caryn (2015). "Corruption and Collective action". DLP Research Paper 32. Developmental Leadership Program.

Médard, J.F. (1998). Corruption in the Neo-Patrimonial States of SubSaharan Africa. En A. Heidenheimer, \& M. Johnston (Eds.), 
Political corruption: concepts \& contexts. New Jersey: Transaction Publishers.

Médard, J.F. (2002). Political corruption: concepts \& contexts. New Jersey: Transaction Publishers.

Milgram, S. (1977). En T. Blass (Ed.), The individual in a Social World: essays and experiments. $3^{\mathrm{a}} \mathrm{ed}$. Londres.

Ministerio del Interior y de Justicia, República de Colombia (2011).

Estatuto Anticorrupción. Ley 1474 por la cual se dictan normas orientadas a fortalecer los mecanismos de prevención, investigación y sanción de actos de corrupción y la efectividad del control de la gestión pública.

Mungiu-Pippidi, A. (2006). Corruption: Diagnosis and Treatment. Journal of Democracy.17 (3)86-99. https://doi.org/10.1353/jod.2006.0050

Mungiu-Pippidi, A. (2011). Contextual Choices in Fighting Corruption: Lessons Learned. Norad. Norwegian Agency for Development Cooperation.

Mungiu-Pippidi, A. (2013). Controlling Corruption thought Collective Action. Journal of Democracy, 24(1). https://doi.org/10.1353/jod.2013.0020

OCDE (2003). Anti-corruption Instruments and the OECS Guidelines for Multinational enterprises. Recuperado http://www.oecd.org/corporate/mne/2638728.pdf (2013). Anti-Corruption Ethics and Compliance Handbook for Business 2013. Recuperado http://www.oecd.org/corruption/AntiCorruptionEthicsComplianc eHandbook.pdf

Ostrom, E. (1990). Governing the Commons. The Evolution of Institutions for Collective Action. Cambridge: Cambridge University Press. https://doi.org/10.1017/CBO9780511807763 
Ostrom, E. (1998). A behavioural Approach to the Rational Choice Theory of Collective Action: Presidential Address American Political Association 1997. American Political Science Review, 92 (1). https://doi.org/10.2307/2585925

(2014). Más allá de los mercados y los Estados: gobernanza policéntrica de sistemas económicos complejos. Revista mexicana de sociología, 76(1)15-70. Artículo publicado en su versión original bajo el título Beyond Markets States: Polycentric Governance of Complex Economic Systems. En: K. Grandin (Ed.), Les Prix Nobel. The Nobel Prizes 2009 (pp. 408-444).

Orlando Alfaro, S. (2004). Corrupción y Desarrollo: Deconstruyendo el discurso del Banco Mundial. Realidad: Revista de Ciencias Sociales y Humanidades. Universidad Centroamericana José Simeón Cañas.

Persson, A., Rothstein, B., \& Teorell, J. (2013). Why Anticorruption Reforms Fail- Systemic Corruption as a Collective Action Problem. Governance: An International Journal of Policy, Administration, and Institutions, 26(3) 449-471. https://doi.org/10.1111/j.1468-0491.2012.01604.X

Putnam, R. (1993). Making Democracy Work: Civic Traditions in Modern Italy. Princeton: Princeton University Press.

Rodríguez, N., \& Orsi, O. (Eds.) (2014). El Ministerio Fiscal en el combate a la corrupción: experiencias y perspectivas desde los sistemas penales de Iberoamérica (pp. 85-124).

Roitman, M. (6 de febrero de 2015). La transparencia, una excusa para la corrupción. Eldiario.es. Recuperado de https://www.eldiario.es/contrapoder/transparencia-democracialucha contra la corrupcion $6 \quad 353174700 . h t m l$. Última visita: 10/04/15.

Rose-Ackerman, S. (1978). Corruption: A study in political economy. New York: Academic Press.

(1999). La Corrupción y los Gobiernos: Causas, consecuencias y reforma. Cambridge University Press. 
Rothstein, B., \& Teorell, J. (2008). What Is Quality of Government? A Theory of Impartial Government Institutions. Governance 21(2) 165-190. https://doi.org/10.1111/j.1468-0491.2008.00391.x

Rothstein, B., \& Stolle, D. (2008). The State and Social Capital: An Institutional Theory of Generalized Trust. Comparative Politics, 40(4) 441-459. https://doi.org/10.5129/001041508X12911362383354

Rothstein, B., \& Uslaner, E. (2006). All for All: Equality, Corruption, and Social Trust. World Politics, 58(1) 41-72. https://doi.org/10.1353/wp.2006.0022

Rothstein, B. (1998). Just Institutions Matter the Moral and Political Logic of the Universal Welfare State. Cambridge University Press. https://doi.org/10.1017/CBO9780511598449

Rothstein, B. (2000). Trust, social dilemmas and collective memories. Journal of Theoretical Politics, 12(4) 477-501.

Rothstein, B. (2007). Anti-Corruption - A Big Bang Theory. En The Quality of Government Institute. Goteborg University.

Rothstein, B. (2011)._Quality of Government and Epistemic Democracy. En The Quality of Government Institute. Recuperado de http://www.yale.edu/polisci/conferences/epistemic_democracy/b Rothstein.pdf

Shadabi, L. (2013) «The Impact of Religion on Corruption» The Journal of Business Inquiry, 12, 102-117

Shleifer, A., \& Vishny, R.W. (1993). Corruption. The Quarterly Journal of Economics, 108(3). 599-617. https://doi.org/10.2307/2118402

Smith, J. D. (2007). A culture of corruption: everyday deception and popular discontent in Nigeria. New Jersey: Princeton University Press.

Transparencia Internacional (2010) Integrity pacts in the water sector.

Transparencia Internacional (2013) Global Corruption Report: Education. 
Transparencia Internacional (2014) Preventing Corruption in Humanitarian Operations. Handbook of Good Practices

Uslaner, E.M. (2008a). Corruption, Inequality, and the Rule of Law: The Bulging Pocket Makes the Easy Life. Cambridge: Cambridge University Press. https://doi.org/10.1017/CBO9780511510410

Uslaner, E.M., \& Rothstein, B. (2012). Mass Education, State-Building and Equality: Searching for the Roots of Corruption. En The Quality of Government Institute. University of Gothenburg.

UNODC. (2004). Handbook on Practical Anti-Corruption Measures for Prosecutors and Investigators. Recuperado de http://www.unodc.org/pdf/crime/corruption/Handbook.pdf

Weber, M. (1905). La ética protestante y el espíritu del capitalismo [Trad. Joaquín Abellán]. $1^{\text {a }}$ ed. El libro de bolsillo. 